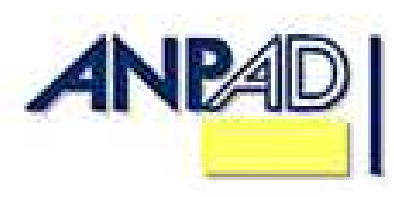

Available online at http://www.anpad.org.br/bar

BAR, Rio de Janeiro, v. 9, n. 2, art. 1, pp. 127-146, Apr./June 2012

$(c)$ E

\title{
Exploring the Black Box in Brazilian Work Groups: a Study of Diversity, Conflict and Performance
}

\author{
Filipe Sobral * \\ E-mail address: filipe.sobral@fgv.br \\ Fundação Getulio Vargas - EBAPE/FGV \\ Rio de Janeiro, RJ, Brazil. \\ Daan Bisseling \\ E-mail address: d.bisseling@br.vescom.com \\ Fundação Getulio Vargas - EBAPE/FGV \\ Rio de Janeiro, RJ, Brazil.
}

* Corresponding author: Filipe Sobral

Escola Brasileira de Administração Pública e de Empresas - Fundação Getulio Vargas, Praia de Botafogo, 190, 506, Rio de Janeiro, RJ, 22253-900, Brazil.

Copyright (C) 2012 Brazilian Administration Review. All rights reserved, including rights for translation. Parts of this work may be quoted without prior knowledge on the condition that the source is identified. 


\begin{abstract}
Over the last few decades, several studies have been conducted to examine the complex relationships between team diversity and individual and organizational outcomes. Although, in theory, team diversity can foster positive organizational synergies by increasing the variance of perspectives and approaches to work different members can bring, the same idiosyncratic characteristics can also engender significant difficulties resulting from problems in coordination, communication and conflict. This study used a sample of 44 work groups to examine the influence of five types of diversity on team outcomes and the mediating role of task and relational conflict on this relationship. A survey of 279 team members and interviews with the 44 team managers were used to examine these relationships. Findings suggest that different forms of diversity impact task conflict in different ways, which in turn is negatively associated with job satisfaction and team performance. Results further show that diversity is unrelated to relational conflict; however, this type of conflict seems to hinder both job satisfaction and team performance. Overall, these patterns suggest a complex link between team diversity and how work groups function.
\end{abstract}

Key words: work groups; team diversity; intragroup conflict; performance; job satisfaction. 


\section{Introduction}

During the last few decades, organizations have embraced new structural forms in order to reduce costs while maximizing flexibility and responsiveness to customer demands. These new organizational forms are built around work groups (Albuquerque \& Puente-Palacios, 2004; Ancona \& Caldwell, 1992; Webber \& Donahue, 2001). One of the underlying assumptions of these new structural forms is that groups can gather together the diversity of perspectives, expertise, and experiences necessary to produce effective organizational outcomes (Levine, Resnick, \& Higgins, 1993). This theoretical perspective is known in team literature as the cognitive diversity hypothesis (Cox \& Blake, 1991), and contends that the different cognitive attributes that members bring to the team can foster creativity, innovation and problem solving, and thus results in superior performance.

However, while team member diversity can potentially create value and benefits for teams, they can also pose a threat to adequate team functioning and often result in suboptimal performance (Horwitz \& Horwitz, 2007; Jehn, Northcraft, \& Neale, 1999). In fact, diversity is often portrayed as a 'double edged sword' by organizational researchers. Some theoretical perspectives, such as the attraction-selection theory or the social identity theory, postulate that people prefer similarity in their interaction, suggesting that member heterogeneity has an adverse impact on team outcomes (Byrne, 1971). These theoretical perspectives suggest that homogenous groups can outperform heterogeneous teams due to higher cohesion within the group.

In light of these competing theoretical perspectives, it is not surprising that empirical findings have also been inconsistent, perpetuating the lack of consensus on how team diversity can influence team processes and outcomes (Joshi \& Roh, 2009; Horwitz \& Horwitz, 2007). Some studies have reported that team diversity is positively associated with performance (e.g. Van der Vegt, Van de Vliert, \& Huang, 2005), while others reported that team diversity has been found to negatively affect performance (e.g. Leonard, Levine, \& Joshi, 2004). The majority of these studies, however, have reported a non-significant relationship between team diversity and performance (De Wit \& Greer, 2008; Joshi \& Roh, 2009). Furthermore, even within these studies, the effects of gender, age, tenure, or other forms of diversity on team outcomes have varied (e.g. Ely, 2004; Kearney, Gerbert, \& Voelpel, 2009; Kirkman, Tesluk, \& Rosen, 2004; Schippers, Den Hartog, Koopman, \& Wienk, 2003).

In light of these conflicting findings regarding the main effects of diversity on organizational performance, several researchers have been proposing that a more complex framework is needed to study the impact of work team diversity (Williams \& O'Reilly, 1998). Specifically, they stress that it is important to go beyond the so called black box studies, which do not measure the intervening process variables (Lawrence, 1997), by incorporating some contextual aspects (e.g., culture or group characteristics), different types of diversity (task-oriented and relations-oriented diversity), and some intervening variables (e.g., intragroup conflict) (De Wit \& Greer, 2008; Jehn et al., 1999; Williams \& O’Reilly, 1998).

The objective of our study is to provide and test a more detailed model of the process by which different types of diversity affect performance in a culturally specific context, the Brazilian organizations. In other words, it is our objective to untangle the complex set of relationships among diversity and organization outcomes. Our research model proposes that work group diversity indirectly affects team performance and members' satisfaction through two types of conflict: task conflict and relational conflict. Thus, we test a model that explores the black box between diversity and group outcomes via an intervening variable, intragroup conflict. 


\section{Conceptual Background and Hypotheses}

\section{Key concepts}

Team member diversity is an aggregate team-level construct that represents differences among members of an interdependent work group with respect to a specific personal attribute (Jackson, Joshi, \& Erhardt, 2003; Joshi \& Roh, 2009). In line with past research, we distinguish between task-oriented diversity and relations-oriented diversity. Task-oriented diversity, or informational diversity, refers to differences in knowledge bases that members bring to the group, such as differences in experience, skill, or information relevant to cognitive tasks. The attributes of this type of diversity (e.g. functional background, education, organizational tenure) are considered to be a team's cognitive resource base and have the potential to create value through the exchange of information and perspectives among team members. In contrast, relations-oriented diversity, also referred to as demographic diversity (Pelled, Eisenhardt, \& Xin, 1999) or social category diversity (Jehn et al., 1999), can be described as the extent to which a work group is heterogeneous with respect to attributes such as gender, age, and race. These attributes are cognitively accessible, pervasive, and immutable and are associated with social categorization processes. These social categorization processes can be manifested in bias and negative attitudes toward others within the group who are dissimilar, and thus may have a negative impact on the group outcomes (Joshi \& Roh, 2009).

Each of these types of diversity present distinct challenges and opportunities for work groups, and consequently should influence team outcomes in different ways. On the other hand, it is important to consider some intervening variables to better understand the relationship between these variables. Intragroup conflict is assumed to be one intervening variable that may help untangle the black box between diversity and team outcomes (Jehn et al., 1999; Pelled et al., 1999).

Intragroup conflict can be defined as an awareness of perceived discrepancies or incompatibilities between members of an interdependent group. Since team members contribute with task and social inputs, it is possible to distinguish between conflict based on substantive disagreements and conflict based on interpersonal incompatibilities (Guetzkow \& Gyr, 1954). The first type of conflict is often referred to as task, substantive, or cognitive conflict (Janssen, Van de Vliert, \& Veenstra, 1999; Jehn, Chadwick, \& Thatcher, 1997; Pelled, 1996; Pelled et al., 1999) and is defined as substantive disagreements about the content of the task that the group is performing, including issues such as the allocation of resources, application of procedures, and the implementation of policies (Guimarães \& Martins, 2008; Janssen et al., 1999). The second type of conflict is referred to as relational (Jehn et al., 1997; Jehn \& Mannix, 2001) or emotional conflict (Pelled, 1996; Pelled et al., 1999) and is characterized by interpersonal divergences among group members that typically include tension, anger, animosity, and other negative feelings (Guimarães \& Martins, 2008; Pelled et al., 1999). Examples of relational conflict are clashes of interpersonal styles, personal values, and ideological preferences, among others.

\section{Diversity and conflict}

The belief that team diversity can foster organizational outcomes is anchored in the idea that diversity will provide teams with a variety of viewpoints and perspectives, and thus enable teams to explore a broader skill base (Cox \& Blake, 1991). The underlying assumption is that heterogeneous teams are composed by members with more diverse life and organizational experiences than homogeneous teams (Milliken \& Martins, 1996). When different perspectives and experiences come into play in a work group, conflicts within the group may arise (Pelled et al., 1999).

Nevertheless, some types of diversity are more likely to result in certain types of conflicts than others. As such, an increase in task related conflicts is more likely to come from heterogeneous teams consisting of members with differing educational backgrounds, functional backgrounds and organizational tenures (Jehn et al., 1997; Jehn et al., 1999; Pelled et al., 1999; Williams \& O'Reilly, 
1998). This happens because disagreements about the task content are likely to emerge when workgroups are composed by members with different experiences and knowledge. Therefore, we expect that if team members have incongruent opinions or if they have opposing task perceptions, the potential for task conflict will likely increase:

Hypothesis 1: Informational (job related) diversity will increase task conflict in workgroups.

On the other hand, social category diversity is more likely to incite social categorization and, therefore, result in relationship conflicts. Demographic attributes such as race, gender, or age are often used for social categorization (Jehn et al., 1997). Pelled (1996) describes social categorization as a natural tendency for individuals to structure their perceptions of themselves and others by means of abstract social categories. According to Tsui, Egan and O'Reilly (1992) this can lead group members to perceive members from different social categories as less trustworthy, honest, and cooperative than members of their own category. This can lead to discrimination and segregation within the work group, disrupting the interaction between group members. Therefore, we expect that this intragroup hostility and animosity will likely increase the interpersonal conflicts between group members:

Hypothesis 2: Social category (non job related) diversity will increase relational conflict in workgroups.

\section{Conflict and team outcomes}

Despite the early belief that conflict hinders performance and reduces satisfaction among team members (Hackman \& Morris, 1975; Pondy, 1967), several researchers have theorized that conflict is beneficial under certain circumstances (Tjosvold, 1991; Van de Vliert \& De Dreu, 1994). Eisenhardt Kahwajy and Bourgeois (1997) argue that task conflict provides more information, a deeper understanding of issues, and a richer set of possible solutions. A lack of conflict can increase cohesiveness and might make the task of organizing easier, but will also result in groupthink and greater task uncertainty. In other words, when task conflict is absent, teams might not realize that inefficiencies exist.

Moderate levels of task conflict have been shown to be beneficial to group performance, especially when working on complex and non-routine tasks (Jehn, 1995, 1997). This is because it can improve decision quality due to the fact that the synthesis that emerges from conflict is generally superior to individual perspectives of team members (Schwenk, 1990). However, relational conflict is considered to be detrimental to both performance and member satisfaction (Jehn, 1995). The anxiety produced by interpersonal incompatibilities may inhibit cognitive functioning and distract members from the task, which causes them to perform less effectively (Staw, Sandelands, \& Dutton, 1981).

Research on individuals' affective reactions to intragroup conflict reveals that, in general, both types of conflict hinder the satisfaction of team members (De Dreu \& Weingart, 2003; Jehn et al., 1997; Pelled et al., 1999). Defined as "a pleasurable or positive emotional state resulting from the appraisal of one's job or job experiences" (Locke, 1976, p. 1300), job satisfaction is influenced by the way people experience and deal with conflict in their work groups. While relational conflict promotes uncomfortable feelings that may lead to frustration, strain and uneasiness, inhibiting the ability of the group members to enjoy each other and their work in the group, task conflict may also cause tension, antagonism and unhappiness among group members and an unwillingness to work together in the future. In fact, Ross (1989) suggests that the normal reaction to any form of disagreement is frustration and dissatisfaction. An increase in the level of conflict (whether emotional or cognitive) will cause more friction within the team if not dealt with correctly, and will make the team members feel less comfortable. Their morale will decrease and as a consequence their job satisfaction will also.

Despite the consensus that both types of conflict hinder job satisfaction, findings have been divergent regarding which type of conflict is more relevant to dissatisfaction among team members. The vast majority of these studies report that relational conflict tends to have a stronger impact on dissatisfaction than task conflict (De Dreu \& Weingart, 2003; Guimarães \& Martins, 2008). 
Nevertheless some studies found that task conflict can be more detrimental to members' satisfaction than relational conflict (Nijdam, 1998; Silva, 2009; Vermeul, 1996).

In our study, it is hypothesized that both types of conflict will have a negative impact on team members' satisfaction. However, we expect that relational conflict will have a stronger negative impact on member satisfaction than task conflict. Due to the collectivist nature of Brazilian culture, it is expected that team members in Brazilian organizations will feel more distressed and uncomfortable with conflict that jeopardizes their tight social network (Holt \& DeVore, 2005). Since belonging to groups and preserving harmony is critical to this culture, relational conflict will likely create a higher dissatisfaction than other forms of substantive disagreements.

Hypothesis 3 (H3): Both task and relational conflict will be negatively related to members' job satisfaction; however, the relationship with members' satisfaction will be stronger in the case of relational conflict than task conflict.

Regarding the relationship between task conflict and team performance, empirical findings have been somewhat contradictory. For example, Eisenhardt et al. (1997) found that top management teams with low levels of task conflict are associated with poor decision making, hereby suggesting that task conflict and performance are positively related. The authors argued that task conflict leads to a higher performance because members are more likely to offer and evaluate various solutions, thus reaching optimal decisions and outcomes. Jehn (1994) and Tjosvold, Law and Sun (1999) also reported a positive relationship between task conflict and performance. However, several others claim that task conflict hinders performance, as team members will work less effectively and produce suboptimal outcomes (Janssen et al., 1999; Jehn, 1995; Jehn et al., 1999). Jehn (1995) adds that the type of task a group performs influences the relationship between conflict and performance, suggesting that groups performing non-routine tasks will benefit more from the diversity of ideas and perspectives of others than groups performing routine tasks.

However, Jehn et al. (1997) also place a limitation on the experience of intragroup conflict. Groups with high levels of task conflict might perform well objectively, but have the perception of a poor performance. On the other hand, group members who perceive low levels of task conflict may mistakenly believe their group performed well, despite inadequate levels of discussion, debate and critical evaluation. As the team members feel less satisfied with the job they perform, they will perceive the performance in a more negative manner, and indicate a lower performance.

Regarding relational conflict, research findings have been more consistent, suggesting that when group members have interpersonal problems with one another, they tend to lose perspective about the task being performed and their cognitive processes of complex information tend to be weakened (Staw et al., 1981). Supporting this position, Pelled (1996) and Jehn et al. (1999) presented findings of a highly significant negative association between relational conflict and group performance. Amason (1996) also found significant negative correlations between relational conflict (referred to as affective or dysfunctional conflict) and performance, stating that relational conflict negatively influences the quality of decisions made and causes lower commitment.

Since a harmonious relationship among group members is of utmost importance in collectivistic cultures, such as Brazil, it would be expected that team members will avoid confrontation and conflict and emphasize harmony within the group (Sobral, Carvalhal, \& Almeida, 2008; Westwood, Tang, \& Kirkbride, 1992). This conflict avoidance strategy is reinforced by a high hierarchical distance between members and team leaders, as a way of showing obedience and loyalty (Barros \& Prates, 1996). In these cultures, task performance will be secondary to the conciliatory image portrayed within the group (Nibler \& Harris, 2003; Shenkar \& Ronen, 1987). Therefore, it is assumed that a culture that stresses the potential harm of conflict and the avoidance of conflict at all costs is likely to experience only the negative effects of conflict. Groups operating within this cultural context are unlikely to experience the positive consequences of task conflict. Consequently, it is hypothesized that in Brazil, both relational and task conflict will be negatively correlated with team performance. 
Hypothesis 4 (H4): Both task and relational conflict will be negatively related to team performance.

\section{Conflict as a mediator of the relationship between diversity and team outcomes}

The conflicting empirical findings in diversity studies have been used to contend that there are no main effects of team diversity on organizational outcomes (Williams \& O'Reilly, 1998). However, the majority of these studies have failed to open the Black Box of diversity, and investigate the effect of diversity on team outcomes as explained by its effect on different group processes, such as intragroup conflict. Lawrence (1997) was among the first to criticize how organizational researchers have been interpreting the relationship between diversity variables and organizational outcomes, stressing that these interpretations often include subjective concepts, however, most organizational diversity studies neither measure nor test the related inferences.

Different types of intragroup conflict are, both implicitly and explicitly, assumed to be a natural consequence of diversity in team members. Therefore to better understand the effects of diversity and team outcomes, we believe that it is important to understand the dynamic relationships between diversity and conflict and between conflict and team outcomes.

Hence, the model proposed and tested in this study moves away from the mentioned Black Box studies, rejecting the existence of a direct relationship between diversity and organizational outcomes. In our model, the relationship between diversity and team outcomes is mediated by the intragroup conflict. Since we hypothesized that diversity gives rise to conflict and that conflict is linked to team satisfaction and performance, we hypothesize the effects of work group diversity will be mediated by the types of intragroup conflict that they give rise to. Therefore, we propose the following hypotheses:

Hypothesis 5 (H5): Task conflict will mediate the effects of informational diversity on team performance and job satisfaction.

Hypothesis 6 (H6): Relational conflict will mediate the effects of social category diversity on team performance and job satisfaction.

The presented six hypotheses constitute an intervening process model of work group diversity, conflict, and team outcomes.

\section{Method}

\section{Participants}

Participants of this study included members of 44 work groups from eight Brazilian companies belonging to high technology industries. The choice of high technology companies was made because they operate in particularly ambiguous environments in which there are hardly any certainties, and procedures are often not fixed, making conflict more prevalent (Eisenhardt, Kahwajy, \& Bourgeois, 1997). All of the researched companies had more than 10,000 employees to avoid influence of size differences between companies.

For the purposes of this research, work groups were defined as intact social entities with boundaries embedded in one or more larger social systems, with two or more members who are interdependent in their tasks and share responsibility for outcomes (Hackman, 1987). We use the labels team and group interchangeably in this study, despite recognizing that there may be degrees of difference, rather than fundamental divergences, in the meanings implied by these terms (Guzzo \& Dickson, 1996). For example, Katzenbach and Smith (1993) assert that groups become teams when they develop a sense of shared commitment and strive for synergy among members. In other words, 
teams are groups where members are interdependent and share goals, tasks and outcomes (Albuquerque \& Puente-Palacios, 2004).

A total number of 279 team members participated in this study, which represented an average response rate within groups of $82 \%$. The teams in our sample had an average size of approximately 8 members (s.d. $=2.1$ ), with 33 percent being female, on average (s.d. $=13$ percent). The average team member had a mean age of 35 years (s.d. $=4.7)$ and a mean tenure of 8.2 years (s.d. $=5.1$ ).

\section{Procedures}

To test the hypotheses and examine the impact of diversity and conflict on team performance and member satisfaction, a survey was distributed to team members of the companies researched. It was explained to participants that the survey was voluntary and that data would be treated anonymously. Questionnaires were administered in Portuguese. The translation and back-translation procedure was employed and some minor adjustments were made to items' descriptions to ensure accuracy of meaning.

In order to add qualitative support to the quantitative data from the survey, semi-structured interviews were held with managers of the teams researched. The interviews had the purpose of capturing more sensitive, and sometimes elusive, aspects of group conflict, thereby improving the study's internal validity. In these interviews managers were asked to describe the nature of cooperation in their teams. Special attention was given to group dynamics as to how the group dealt with differences of opinions and interpersonal disagreements. The questions used to guide the interviews were based on Jehn's work (1995). Finally, the managers were asked to evaluate the performance of their teams.

\section{Measures}

The survey instrument that was developed for this study consisted of 32 self-reported questions ordered randomly. Each item score was collected separately per team member.

Diversity. To determine the level of diversity within each team in terms of age, gender, education level, functional background, and organizational and departmental tenure, six categorical variables were measured. For measuring heterogeneity, Blau's formula of heterogeneity was used (Knight et al., 1999). Blau's formula subtracts 1 by the sum of squares of the proportions. Blau's formula is $1-\Sigma i^{2}$, where $i$ is proportion. To clarify this formula, an example of functional background is presented: assume that one team consists of three people with a background in economics $(i=3 / 6)$, two others have an engineering background $(i=2 / 6)$, and the last person has a marketing background $(i=1 / 6)$. The heterogeneity ratio would in this case be: $1-\Sigma(3 / 6)^{2}+(2 / 6)^{2}+(1 / 6)^{2}=1-0.39=0.61$.

Conflict. The relational conflict scale (10 items) combined items from the Knight et al. (1999) study to determine the interpersonal conflict of a unit and the Jehn et al. (1997) study on relationship conflict. Task conflict scale (6 items) derives from the study of Pelled, Eisenhardt and Xin (1999). Each of these scales used 5-point Likert questions. The coefficient alphas for relational and task conflict were 0.82 and 0.79 , respectively. To obtain group-level measures from individual-level responses we averaged individual scale scores across the group members of a particular group and tested whether the aggregation of individual-level measures to the group level was appropriate. We computed the intraclass correlation coefficients ICC(1) and eta squared coefficients (Bliese, 2000) for both conflict types. A statistically significant F-test for eta squared and ICC(1) indicates that the between-group variance of a measure is greater than its within-group variance (Klein, Conn, Smith, \& Sorra, 2001). The ICC(1) values ranged from 0.19 (for task conflict) to 0.24 (for relational conflict) and the eta squared ranged from 0.31 (for task conflict) to 0.35 (for relational conflict), and were all statistically significant (sig. < 0.001). Overall, both measures justified the aggregation of the variables, indicating that any two individuals within the same group are more similar in responses than two people from different groups. 
Task routineness. Task routineness was included as a control variable since several studies report that the type of task can influence the relationship between conflict and performance. To measure task routineness we used 3 Likert-style questions from the Jehn et al. (1997) study. The coefficient alpha for task routineness was 0.87. Aggregation to the group level was justified by an eta squared of 0.33 and a ICC(1) of 0.22 .

To ensure the convergent and discriminant validity of task conflict, relational conflict and task routineness measures, first an exploratory factor analysis (EFA), and then a confirmatory factor analysis (CFA), was conducted on all participant responses $(\mathrm{N}=279)$. The EFA yielded a 3-factor solution that accounted for $72.40 \%$ of the total variance. All indicators loaded on their theoretical constructs (factors loadings varied from 0.658 to 0.902 ). No secondary loadings above 0.40 were detected. Since the results of the EFA confirmed the proposed theoretical model, we then proceeded with a CFA in order to assess the fit of the factorial structure. The CFA, using a maximum likelihood estimation method, produced a Chi-square of 1.58 per degree of freedom, a goodness of fit index (GFI) of 0.91 and a root-mean-square residual (RMSEA) of 0.048. Additionally, all indicators presented factor loadings statistically significant at $1 \%$, indicating a good fit between the data and the theoretical factor structure.

Satisfaction. Job satisfaction scale comprised six items based on the study of Tsui et al. (1992). To ensure the validity of the scale, a factor analysis was also performed on all participant responses ( $\mathrm{N}$ $=279$ ). The resulting one dimensional factor explained $69.4 \%$ of the total variance and factor loadings varied from 0.83 and 0.65 . The coefficient alpha was 0.80 and the average item-total correlation was 0.69. Aggregation to the group level was justified by an eta squared of 0.29 and a ICC(1) of 0.20 .

Performance. To measure perceived team performance, the following question was asked to team members on a 5-point Likert scale: How well do you think your unit performs? Aggregation to the group level was justified by an eta squared of 0.32 and an ICC(1) of 0.25 . Additionally, each manager rated the actual team performance on a 5-point scale during the interviews.

\section{Analysis}

To test the proposed hypotheses, multiple regression analyses were used. To test the $\mathrm{H} 1$ and $\mathrm{H} 2$, social category diversity (age and gender diversity) and informational diversity (educational, organizational tenure and functional diversity) were treated as the independent variables, while measures of task and relational conflict were treated as the dependent variables. To test $\mathrm{H} 3$ and $\mathrm{H} 4$, both measures of conflict were considered as independent variables, while measures of performance (perceived and manager's evaluation) and satisfaction were treated as the dependent variables. All regression analyses used variables aggregated to the group level to avoid problems of asymmetric perceptions of conflict within a work group (Jehn, Rispens, \& Thatcher, 2010).

Finally, to test if task and relational conflict would act as mediators between diversity and team outcomes, the standard procedure used to test mediating effect was used. First, regressing the mediator (conflict) on the independent variable (diversity), second, regressing the dependent variable (team outcomes) on the independent variable, and finally regressing the dependent on both the mediator and the independent variable (Baron \& Kenny, 1986). Mediation requires the following conditions: (1) the independent variable has an effect on the mediator in the first equation; (2) the independent variable affects the dependent variable in the second equation; (3) the mediator affects the dependent variable in the third equation; (4) the effect of the independent variable on the dependent variable is smaller in the third equation than in the second. Perfect mediation exists if the independent variable has no direct effect on the dependent variable in the third equation (Baron \& Kenny, 1986). To avoid problems associated with multicollinearity among the two highly correlated conflict variables, we ran separate regression models for each of them.

An important methodological concern of this study regards the reliability of the data gathered through the questionnaire-based survey, especially the potential common method variance problem of the collected data structure. To address this issue we developed a two-step strategy. First, the 
questionnaire was prepared taking into account the main causes of common method variance, i.e., common rater effect, item characteristic effect, item context effect and measurement context effect (Podsakoff, MacKenzie, Lee, \& Podsakoff, 2003). For example, we limited social desirability bias (an important component of common rater effect) explaining in the questionnaire introduction that: (a) the survey was developed with academic purposes and not to make judgments on individuals or institutions, (b) questionnaire responses were not linked to the identity of the respondent, and (c) data would be treated with strict confidentiality. We also avoided item ambiguity (an important component of item characteristic effect) through the pre-test of the questionnaire in the language of application with business graduate students. After the completion of the survey, we performed the Harman's onefactor test as ex post control of the final database. Neither a single factor from the factor analysis nor a general factor in accounting for the covariance of independent variables emerged from our analysis which minimizes the occurrence of common method variance disturbances (Podsakoff \& Organ, 1986).

\section{Results}

Table 1 provides the regression analyses that tested the impact of diversity on team conflict. Hypothesis 1 predicted that informational diversity would have positive associations with task conflict in work groups. This hypothesis was partially supported, since the only positive association between informational diversity and task conflict was functional background diversity $(\beta=0.283 ; p<0.01)$. Unexpectedly, the relationships between organizational tenure diversity and task conflict was nonsignificant, while those between educational diversity and task conflict was significant, however negative $(\beta=-0.312 ; \mathrm{p}<0.01)$. According to these results, functional background diversity seems to be a key driver of task conflict, while educational diversity seems to hinder it. The fact that different types of informational diversity seem to have different impacts on task conflict makes it difficult to accept H1. Contrary to our initial expectations, a negative association between gender diversity and task conflict was also found $(\beta=-0.278 ; \mathrm{p}<0.01)$, suggesting that when groups are more diverse in terms of gender composition, task conflict will likely decrease.

On the other hand, Hypothesis 2, on the influence of social category diversity on relational conflict was not supported $(\beta=-0.202 ; p>0.05$ and $\beta=0.196 ; p>0.05$, respectively). According to these results, social category diversity seems to have no effect on interpersonal conflicts within Brazilian work groups. Since the sample size was limited to 44 work groups, we computed the statistical power of the regression analysis using $G^{*}$ Power 3 software to determine Type II error probability (Faul, Erdfelder, Lang, \& Buchner, 2007). For a level of significance of 0.05 and a large effect size (0.35), the statistical power of the $\mathrm{R}^{2}$ test was 0.82 , above the required 0.80 suggested by Cohen (1992). However, the power of the test is not satisfactory for medium (0.15) and small (0.02) effect sizes. We used Cohen's magnitude of effects, as we didn't have enough studies in Brazil that could be used as reliable benchmarks of the effect size.

Table 1

\section{Regression Analyses Predicting Conflict}

\begin{tabular}{lcc}
\hline & Task Conflict $(\mathbf{N}=\mathbf{4 4})$ & Relational Conflict $(\mathbf{N}=\mathbf{4 4})$ \\
\hline Predictors & & \\
Age diversity & .134 & -.202 \\
Gender diversity & $-.278^{* *}$ & .196 \\
Educational diversity & -.167 & .072 \\
\hline
\end{tabular}




\section{Table 1 (continued)}

\begin{tabular}{lcc}
\hline & Task Conflict $(\mathbf{N}=\mathbf{4 4})$ & Relational Conflict $(\mathbf{N}=\mathbf{4 4})$ \\
\hline Organizational tenure diversity & $-.312^{* *}$ & .188 \\
Functional background diversity & $.283^{* *}$ & .180 \\
R-squared & .255 & .080 \\
F test & $10.23^{* *}$ & 1.21 \\
\hline
\end{tabular}

Note. $*$ p-values $<0.05 ; * *$ p-values $<0.01$.

All entries are standardized regression coefficients. One-tailed tests were used for effects predicted in directional hypotheses. Considering a level of significance of 0.05 and a large effect size (0.35), the statistical power of the $\mathrm{R}^{2}$ test was 0.82 .

Table 2 provides the regression analyses that tested the impact of conflict on team outcomes (worker morale and group performance). Hypothesis 3 predicted that both task and relational conflict are negatively related to job satisfaction and that this relationship is stronger in the case of relational conflict. Consistent with $\mathrm{H} 3$, results show that both relational $(\beta=-0.356 ; p<0.01)$ and task conflict $(\beta=-0.244 ; \mathrm{p}<0.01)$ have a significant negative association with job satisfaction. Also consistent with our initial hypothesis the association is stronger in the case of relational conflict. This finding suggests that relational conflict is more likely to promote dissatisfaction than task conflict in work groups in Brazil. Overall, intragroup conflict (whether emotional or cognitive) seemed to explain approximately $23 \%$ of the variance in job satisfaction in our sample.

Hypothesis 4, on the effects of conflict on team performance, was only partially supported by the regressions. In our sample, both relational and task conflict were negatively associated with members' perceived team performance $(\beta=-0.313$ and $\beta=-0.354 ; p<0.01)$, however, they were not related to managers' appraisals of team performance $(\beta=-0.032$ and $\beta=-0.027 ; p>0.10)$.

Table 2

\section{Regression Analyses Predicting Team Outcomes}

\begin{tabular}{|c|c|c|c|}
\hline & $\begin{array}{c}\text { Job Satisfaction } \\
\quad(\mathbf{N}=\mathbf{4 4})\end{array}$ & $\begin{array}{l}\text { Perceived Performance } \\
\qquad(\mathrm{N}=\mathbf{4 4})\end{array}$ & $\begin{array}{l}\text { Manager Appraisal } \\
(\mathrm{N}=\mathbf{4 4 )}\end{array}$ \\
\hline \multicolumn{4}{|l|}{ Control Variable } \\
\hline Task Routineness & .082 & -.015 & .013 \\
\hline \multicolumn{4}{|l|}{ Main Effects } \\
\hline Relational Conflict & $-.356^{* *}$ & $-.313 * *$ & -.032 \\
\hline Task Conflict & $-.244 * *$ & $-.354 * *$ & -.027 \\
\hline$R$-squared & .234 & .276 & .011 \\
\hline F test & $8.50 * *$ & $11.85^{* *}$ & .406 \\
\hline
\end{tabular}

Note. $*$ p-values $<0.05 ; * *$ p-values $<0.01$.

All entries are standardized regression coefficients. One-tailed tests were used for effects predicted in directional hypotheses. Considering a level of significance of 0.05 and a large effect size (0.35), the statistical power of the $\mathrm{R}^{2}$ test was 0.90 .

Finally, to test if conflict would act as a mediator in the relationship between diversity and team outcomes, the procedure suggested by Baron and Kenny (1986) was used. Since the regressions between task and relational conflict and both measures of team outcomes were already conducted (as presented in Table 2), we first regressed job satisfaction on all variables of diversity. Surprisingly, only the relationship between age diversity and job satisfaction was positively significant $(\beta=0.562 ; \mathrm{p}$ $<0.01$ ), meaning that when work groups are composed by members from different age groups, job satisfaction will increase. However, when relational and task conflict were controlled, this relationship between age diversity remained equally significant, while all other measures of diversity remained 
non-significant, suggesting that neither relational nor task conflict mediate the relationship between diversity and job satisfaction.

Similarly, we regressed members' perceived performance on measures of social category and informational diversity. Despite our initial assumption that social categorization would be associated with lower performance, no direct associations were found, corroborating some previous studies (Balkundi, Kilduff, Barsness, \& Michael, 2007; Choi, 2007). The only significant association found was between functional background diversity and perceived performance $(\beta=-0.450 ; p<0.01)$, suggesting that functional diversity is negatively related to performance in Brazilian work groups. However, when task and relational conflict were controlled, the effect of functional background diversity and perceived performance remained significant, while the effects of the other types of diversity remained non-significant. Thus, the mediating role of task and relational conflict were not confirmed, and therefore neither hypothesis H5 nor H6 were supported. Table 3 presents results of the mediated regression analyses.

Table 3

\section{Results of Mediated Regression Analyses}

\begin{tabular}{|c|c|c|c|c|c|c|c|c|}
\hline \multirow[t]{2}{*}{ Independent Variables } & \multicolumn{4}{|c|}{ Job Satisfaction $(N=44)$} & \multicolumn{4}{|c|}{ Perceived Performance $(\mathrm{N}=44)$} \\
\hline & 1 & 2 & 3 & 4 & 1 & 2 & 3 & 4 \\
\hline \multicolumn{9}{|l|}{ Main Effects } \\
\hline Age diversity & $.562 * *$ & $.575^{* *}$ & $.507 * *$ & $.542 * *$ & .158 & .134 & .115 & .141 \\
\hline Gender diversity & .102 & .087 & .117 & .067 & .116 & .129 & .097 & .071 \\
\hline Educational diversity & -.065 & -.074 & -.047 & -.144 & .120 & .085 & .104 & .028 \\
\hline Organizational tenure diversity & .173 & .169 & .124 & .090 & -.089 & -.043 & -.118 & -.182 \\
\hline Functional background diversity & -.064 & -.093 & -.065 & -.009 & $-.450 * *$ & $-.432 * *$ & $-.401 * *$ & $-.392 * *$ \\
\hline \multicolumn{9}{|l|}{ Mediators } \\
\hline Relational Conflict & & $-.337 * *$ & & ${ }^{-} 289^{* * *}$ & & $-.304 * *$ & & $-.292 * *$ \\
\hline Task Conflict & & & $-.252 * *$ & $-.202^{*}$ & & & $-.254 * *$ & $-.215^{*}$ \\
\hline$R$-squared & .289 & .352 & .312 & .433 & .194 & .237 & .314 & .358 \\
\hline F test & $7.07 * *$ & $8.45^{* *}$ & $8.68^{* *}$ & $9.26^{* * *}$ & $4.18^{* *}$ & $5.38^{* *}$ & $6.07 * *$ & $6.78^{* *}$ \\
\hline
\end{tabular}

Note. $*$ p-values $<0.05 ; * *$ p-values $<0.01$.

All entries are standardized regression coefficients. One-tailed tests were used for effects predicted in directional hypotheses.

\section{Discussion}

The study reported here makes a contribution to existing research on work group diversity by examining the mediating role of intragroup conflict on team outcomes in Brazilian organizations. Researchers have often relied on the argument that diversity increases conflict, which, in turn, influences team outcomes, such as team members' morale and group performance. This study assesses the validity of this argument in a specific cultural context with the objective of untangling the complex black box between diversity and team outcomes. However, the relationships between diversity, conflict and performance are not straightforward. Results show that different forms of diversity have distinctive effects on different types of conflict, which in turn affect job satisfaction and team performance in specific ways.

Our first two hypotheses examined the impact of diversity on both relational and task conflict. Results showed three significant associations in different directions. First, a positive association was found between functional background diversity and task conflict, meaning that team members' 
differences in functional backgrounds should result in a higher level of task conflict. This result is consistent with De Wit and Greer (2008) meta-analysis which reported a positive association between job-related diversity and task conflict. As Pelled et al. (1999) noted: "because functional background is so relevant to work, people are particularly likely to draw on belief structures based on functional background when addressing workplace issues" (p. 20). Therefore, we can conclude that functional background diversity is a key enhancer of task conflict in work groups. This finding suggests that team mangers should use cross-functional teams to avoid groupthink and stimulate differences of opinion within a team.

Second, a negative association between organizational tenure diversity and task conflict was revealed. This means that teams where tenure diversity is lower, i.e., a team composed of members with similar histories in the organization, there will be higher levels of task conflict. A possible explanation for this result can be the fact that teams that have a longer history together have accepted the presence of constructive conflict, which teams with a shorter history have not yet achieved. Contrary to the De Wit and Greer (2008) meta-analysis, which reported a positive association between non-job related diversity and task conflict, we also found evidence of a negative influence of gender diversity on task conflict. This finding seems to suggest that when teams are heterogeneous with respect to gender composition, task conflict will likely decrease, which can be a sign of a certain sensitiveness in the relationship between males and females in Brazilian work groups.

Contrary to our initial hypothesis, but consistent with the De Wit and Greer (2008) metaanalysis, relational conflict was not associated with social category diversity. Despite the theoretical argument that social categorical characteristics, such as gender and age, provide a salient basis for identity, and subsequent hostilities and interpersonal conflicts within a group (Jehn et al., 1999), results did not validate this hypothesis. One possible interpretation is that gender and age composition are unrelated to relational conflict, triggering categorization and social comparison processes that cancel each other's effects (Jehn et al., 1997).

Regarding the impact of conflict on group outcomes, the empirical findings confirmed our hypotheses. Consistent with the meta-analysis of De Dreu and Weingart (2003), significant proof was found for a negative association between both relational and task conflict and job satisfaction. However, results showed a stronger negative association between relational conflict and job satisfaction than was found between task conflict and job satisfaction, which is consistent with the proposed hypothesis, since we would expect that Brazilian workers would feel more distressed and uncomfortable with the type of conflict that jeopardizes their tight social network. Contrary to other studies conducted in Brazil, our study found that both types of conflict were significant predictors of team morale. In one of those studies, Guimarães and Martins (2008) found that only relational conflict was associated with affective responses of team members, while Silva's study (2009) found that only task conflict was associated with job satisfaction.

The negative impact of both types of conflict and satisfaction was confirmed by the interviews with team managers. However, interviewed managers do not always understand the existence of different forms of conflict and some tended to view conflict as a dysfunctional aspect of group work. Particular importance was given by managers to the unity of the group.

The difficulty managers showed in determining the difference between both kinds of conflict is supported by Janssen, Van de Vliert and Veenstra (1999). Even if team members recognize the difference between both kinds of conflict they might react in a similar manner. Task conflict can be taken personally and as a consequence turn into relational conflict (Pelled et al., 1999). Different perspectives and opinions can be seen by team members as an attack on their own personal ideas. They could then feel more insecure about their delivered work and act in a defensive manner. Tension and pressure will increase within the group and job satisfaction among members is likely to decrease.

As for the connection between conflict and performance, it would be expected that relational conflict would be regarded as unwanted or harmful in Brazilian work groups, given the greater value placed on the harmony of the group. This would mean that relational conflict would be negatively 
associated with team performance. Similarly, we also assumed that Brazilians workers would also react negatively to task conflict, since task performance would be secondary to preserving harmony in the work group. Corroborating our hypotheses, our study shows that both types of conflict are negatively associated with team perceived performance, which is consistent with De Dreu and Weingart's (2003) meta-analysis: 20 out of the 25 studies analyzed reported negative associations between relational and task conflict and team performance. The negative association between conflict and perceived performance seems to be related to the same association between conflict and satisfaction. A team member who is less satisfied with his or her job will likely rate the team's performance lower than a member who is fully satisfied.

Finally, although we found that some forms of diversity were related to task conflict and task conflict was related to job satisfaction and team perceived performance, a third condition was not met in verifying a mediating effect: a significant relationship between diversity and team outcomes without conflict included in the equation. Only age diversity was negatively related to members' satisfaction and functional background diversity was negatively associated with perceived performance; however, their effects on satisfaction and performance remained significant when conflict was controlled. Perhaps this third condition was not identified because we were unable to use a full structural equation model.

\section{Conclusion}

\section{Theoretical implications}

Demography scholars have frequently argued that conflict plays a central role in the relationship between diversity and team outcomes. This study was built on this argument, examining the complex relationships between these constructs in Brazilian work groups. Findings suggest that different forms of diversity have distinct impacts on task conflict because of the specific characteristics of each type of diversity and because of the interactions among them. Contrary to our expectations, social category diversity seems to be unrelated to relational conflict. Further, findings also suggest that conflict, whether of emotional or cognitive nature, seems to hinder satisfaction and performance, which challenges the assumption that conflict based on emotions is linked to lower performance, while conflict based on substantive disagreements has a positive impact on team performance.

The optimistic view of team diversity argues that a greater variety of perspectives and skills can increase team performance by stimulating constructive disagreements on important task-related issues; however, our findings point in the opposite direction. Despite evidence that differences in functional background can potentially enhance task conflict (or constructive conflict) within Brazilian work groups, results showed that this type of conflict hinders team performance; which is corroborated by a negative direct association between functional background diversity and team performance. Due to the relational nature of Brazilian culture, task related disagreements are often taken personally. In other words, functional disagreements can be misinterpreted and escalate into relational conflicts. Therefore, multifunctional teams with the potential to develop different approaches to problems tend to treat all conflict as dysfunctional, which ultimately hinders group performance and morale.

Interviews with managers confirmed that most team members were not skilled in dealing with conflict. This can help to explain why the impact of task conflict on team performance was not differentiated from the impact of relational conflict. However, despite these findings, interviewed managers saw room for conflict management training. In fact, the vast majority of the managers interviewed believed that healthy level of constructive (task) conflict would result in a higher performance. Especially in the technologically more complex tasks, managers believed that team members' opinions and suggestions are essential. An absence of debate was seen by most managers as a negative thing that signaled a passive role by their employees. 
Throughout the study the extent to which people recognize the difference between several types of conflict has been discussed. Team members are not always capable of constructively interpreting conflicts that initially were task related. Criticism of their ideas is frequently seen as a personal attack. In order for differences of a constructive nature to result in positive conflict, team members need to be taught to deal with conflict in an effective manner. However, that raises a question: can a group be trained to focus primarily on optimal performance, if they must accept the presence of conflicting ideas? Or is this a utopia?

\section{Limitations}

We acknowledge several limitations of this study. First, the sample size of 44 teams, while substantial for a field investigation, is insufficient to ensure statistical accuracy of the results (Tabachnick \& Fidell, 2000). Though small group samples are usual in studies that focus on group dynamics and conflicts (e.g., Jehn et al., 2010; Pelled et al., 1999; Wu, Tsui, \& Kinicki, 2010), the limited sample size can reduce the statistical accuracy of the proposed relationships. Specifically, significant relationships between constructs may not be detected (Cohen, 1992).

Secondly, the use of job satisfaction and subjective measures of performance is questionable, since some authors describe them as poor judges of performance (Jehn et al., 1997). Though subjective performance ratings have positive correlations with objective measures (Dess \& Robinson, 1984), it would be desirable to replicate our study with objective measures of performance. Also, we used a single item measure of team members' perception of performance as other studies on group performance (e.g., O'Connell et al., 2002), despite recognizing that team performance may be considered by some authors as a multidimensional construct.

Another limitation of our study was the use of self-reported measures that may have some inherent social desirability bias. Again, mixing subjective and objective measurements of performance would be desired to reduce this problem.

Finally, this study used linear regressions to test the proposed hypotheses. It was thus assumed that the relationship between conflict and performance follows a linear pattern. However, the possibility that the relation is curvilinear was not statistically tested. Future research should try to examine the nature of the relationship between conflict and performance, investigating if it is linear, curvilinear, or even something else (De Dreu, 2006).

\section{Managerial implications}

Finally, some contributions to management practice can be drawn from our study. First of all, attention should be given to team composition and team work mechanisms. Managers should learn that composing a work group or project should not be done randomly. As our study suggests, giving serious thought to the team composition, especially in terms of including different functional backgrounds, can potentially generate constructive conflict and provide more information, a deeper understanding of issues, and a richer set of possible solutions. Teams that are too homogeneous run the risk of engaging in groupthink, whereas teams that are too heterogeneous will likely have too many conflicts that inhibit the team from functioning effectively. The diversity policy of a team must be regarded as something of strategic interest.

However, managers should understand that whenever people work together conflict will arise. One type is conflict of an emotional nature that is mainly driven by negative feelings like jealousy, frustration, envy, and fear. Another type is task conflict, which is driven by differences in opinion and ways of thinking. Both managers and employees that are part of the empirical research showed confusion about what conflict really is and in distinguishing between types of conflict. While one task of a leader is to determine a team's composition, another is to make sure the team performs to its fullest potential. One step towards that could be to strive for a limited level of relational conflict, and find ways to leverage constructive (or task) conflict. 


\section{Received 25 March 2010; received in revised form 15 June 2011.}

\section{References}

Albuquerque, F. J. B., \& Puente-Palacios, K. E. (2004). Grupos e equipes de trabalho nas organizações. In J. C. Zanelli, J. E. Borges-Andrade, \& A. V. B. Bastos (Eds.), Psicologia, organizações e trabalho no Brasil (pp. 357-379). Porto Alegre: Artmed.

Amason, A. C. (1996). Distinguishing the effects of functional and dysfunctional conflict on strategic decision making: resolving a paradox for top management. Academy of Management Journal, 39(1), 123-148. doi: 10.2307/256633

Ancona, D. G., \& Caldwell, D. F. (1992). Demography and design: predictors of new product team performance. Organization Science, 3(3), 321-341. doi: 10.1287/orsc.3.3.321

Balkundi, P., Kilduff, M., Barsness, Z. L., \& Michael, J. D. (2007). Demographic antecedents and performance consequences of structural holes in work teams. Journal of Organizational Behavior, 28(2), 241-260. doi: 10.1002/job.428

Baron, R. M., \& Kenny, D. A. (1986). The moderator-mediator variable distinction in social psychological research: conceptual, strategic, and statistical considerations. Journal of Personality and Social Psychology, 51(6), 1173-1182. doi: 10.1037/0022-3514.51.6.1173

Barros, B. T., \& Prates, M. (1996). A arte brasileira de administrar. São Paulo: Atlas.

Bliese, P. D. (2000). Within group agreement, non-independence, and reliability: implications for data aggregation. In K. J. Klein \& S. W. J. Kozlowski (Eds.), Multilevel theory, research, and methods in organizations: foundations, extensions, and new directions (pp. 349-381). San Francisco: Jossey-Bass.

Byrne, J. A. (1971). The attraction paradigm. New York: Academic Press.

Choi, J. N. (2007). Group composition and employee creative behavior in a Korean electronics company: distinct effects of relational demography and group diversity. Journal of $\begin{array}{llll}\text { Occupational and Organizational Psychology, } & \text { 80(2), }\end{array}$ doi: 10.1348/096317906X110250

Cohen, J. (1992). The power primer. Psychological Bulettin, 112(1), 155-159. doi: 10.1037/00332909.112.1.155

Cox, T., \& Blake, S. (1991). Managing cultural diversity: implications for organizational competitiveness. Academy of Management Executive, 5(3), 45-56. doi: 10.5465/AME.1991.4274465

De Dreu, C. K. W. (2006). When too little or too much hurts: evidence for a curvilinear relationship between task conflict and innovation in teams. Journal of Management, 32(1), 83-107. doi: $10.1177 / 0149206305277795$

De Dreu, C. K. W., \& Weingart, L. R. (2003). Task versus relationship conflict, team performance and team member satisfaction: a meta-analysis. Journal of Applied Psychology, 88(4), 741-749. doi: 10.1037/0021-9010.88.4.741 
De Wit, F., \& Greer, L. (2008, August). The black box deciphered: a meta-analysis of team-diversity, conflict and team performance. Proceedings of the Annual Meeting Academy of Management, Anaheim, CA, USA, 68.

Dess, G. G., \& Robinson, R. B., Jr. (1984). Measuring organizational performance in the absence of objective measures: the case of the privately-held firm and conglomerate business unit. Strategic Management Journal, 5(3), 265-273. doi: 10.1002/smj.4250050306

Eisenhardt, K. M., Kahwajy, J. L., \& Bourgeois, L. (1997). Conflict and strategic choice: how top management teams disagree. California Management Review, 39(2), 42-62.

Ely, R. J. (2004). A field of group diversity, participation in diversity education programs, and performance. Journal of Organizational Behavior, 25(6), 755-780. doi: 10.1002/job.268

Faul, F., Erdfelder, E., Lang, A.-G., \& Buchner, A. (2007). G*Power 3: a flexible statistical power analysis for the social, behavioral, and biomedical sciences. Behavior Research Methods, 39(2), 175-191. doi: 10.3758/BF03193146

Guetzkow, H., \& Gyr, J. (1954). An analysis of conflict in decision making groups. Human Relations, 7(3), 367-381. doi: 10.1177/001872675400700307

Guimarães, V. F., \& Martins, M. C. F. (2008). Bases de poder do supervisor, conflitos intragrupais e comprometimento organizacional e com a equipe. Revista Psicologia: Organizações e Trabalho, 8(2), 54-78.

Guzzo, R. A., \& Dickson, M. W. (1996). Teams in organizations: recent research on performance and effectiveness. Annual Review of Psychology, 47(1), 307-338. doi: 10.1146/annurev.psych.47.1.307

Hackman, J. R. (1987). The design of work teams. In J. W. Lorsch (Ed.), Handbook of organizational behavior (pp. 315-42). Englewood Cliffs: Prentice-Hall.

Hackman, J. R., \& Morris, C. G. (1975). Group tasks, group interaction process, and group performance effectiveness: a review and proposed integration. In L. Berkowitz (Ed.), Advances in experimental social psychology (Vol. 8, pp. 45-99). New York: Academic Press.

Holt, J. L., \& DeVore, C. J. (2005). Culture, gender, organizational role, and styles of conflict resolution: a meta-analysis. International Journal of Intercultural Relations, 29(2), 165-196. doi: 10.1016/j.ijintrel.2005.06.002

Horwitz, S. K., \& Horwitz, I. B. (2007). The effects of team diversity on team outcomes: a metaanalytic review of team demography. Journal of Management, 33(6), 967-1015. doi: $10.1177 / 0149206307308587$

Jackson, S. E., Joshi, A., \& Erhardt, N. L. (2003). Recent research on team and organizational diversity: SWOT analysis and implications. Journal of Management, 29(6), 801-830. doi: $10.1016 / \mathrm{S} 0149-2063$

Janssen, O., Van De Vliert, E., \& Veenstra, C. (1999). How task and person conflict shape the role of positive interdependence in management teams. Journal of Management, 25(2), 117-141. doi: $10.1177 / 014920639902500201$

Jehn, K. A. (1994). Enhancing effectiveness: an investigation of advantages and disadvantages of value-based intragroup conflict. The Journal of Conflict Management, 5(3), 223-238. doi: $10.1108 / \mathrm{eb} 022744$

Jehn, K. A. (1995). A multimethod examination of the benefits and detriments of intragroup conflict. Administrative Science Quarterly, 40(2), 256-282. doi: 10.2307/2393638 
Jehn, K. A. (1997). A qualitative analyses of conflict types and dimensions in organizational groups. Administrative Science Quarterly, 42(3), 530-557. doi: 10.2307/2393737

Jehn, K. A., Chadwick, C., \& Thatcher, S. (1997). To agree or not to agree: diversity, conflict, and group outcomes. International Journal of Conflict Management, 8(4), 287-306. doi: 10.1108/eb022799

Jehn, K. A., \& Mannix, E. A. (2001). The nature of conflict: a longitudinal study of intragroup conflict and group performance. Academy of Management Journal, 44(2), 238-251. doi: $10.2307 / 3069453$

Jehn, K. A., Northcraft, G. B., \& Neale, M. A. (1999). Why differences make a difference: a field study of diversity, conflict, and performance in work groups. Administrative Science Quarterly, 44(4), 741-763. doi: 10.2307/2667054

Jehn, K. A., Rispens, S., \& Thatcher, S. (2010). The effects of conflict asymmetry on work group and individual outcomes. Academy of Management Journal, 53(3), 596-616. doi: 10.5465/AMJ.2010.51468978

Joshi, A., \& Roh, H. (2009). The role of context in work team diversity research: a meta-analytic review. Academy of Management Journal, 52(3), 599-627. doi: 10.5465/AMJ.2009.41331491

Katzenbach, J. R., \& Smith, D. K. (1993). The wisdom of teams: creating the high-performance organization. Boston: Harvard Business School Press.

Kearney, E., Gerbert, D., \& Voelpel, S. (2009). When and how diversity benefits teams: The importance of team members' need for cognition. Academy of Management Journal, 52(3), 581598. doi: 10.5465/AMJ.2009.41331431

Kirkman, B. L., Tesluk, P. E., \& Rosen, B. (2004). The impact of demographic heterogeneity and team leader-team member demographic fit on team empowerment and effectiveness. Group and Organization Management, 29(3), 334-368. doi: 10.1177/1059601103257412

Klein, K. J., Conn, A. B., Smith, D. B., \& Sorra, J. S. (2001). Is everyone in agreement? An exploration of within-group agreement in employee perceptions of the work environment. Journal of Applied Psychology, 86(1), 3-16. doi: 10.1037/0021-9010.86.1.3

Knight, D., Pearce, C. L., Smith, K. G., Olian, J. D., Sims, H. P., Smith, K. A., \& Flood, P. (1999). Top management team diversity, group process, and strategic consensus. Strategic Management Journal, 20(5), 445-465. doi: 10.1002/(SICI)1097-0266(199905)20:5<445::AIDSMJ27>3.0.CO;2-V

Lawrence, B. S. (1997). The black box of organizational demography. Organization Science, 8(1), 122. doi: $10.1287 /$ orsc.8.1.1

Leonard, J. S., Levine, D. I., \& Joshi, A. (2004). Do birds of a feather shop together? The effects on performance of employees' similarity with one another and with customers. Journal of Organizational Behavior, 25(6), 731-754. doi: 10.1002/job.267

Levine, J., Resnick, L., \& Higgins, E. T. (1993). Social foundations of cognition. Annual Review of Psychology, 44(1), 585-612. doi: 10.1146/annurev.ps.44.020193.003101

Locke, E. A. (1976). The nature and causes of job satisfaction. In M. D. Dunnette (Ed.), Handbook of industrial and organizational psychology (pp. 1297-1349). Chicago: Rand McNally.

Milliken, F. J., \& Martins, L. L. (1996). Searching for common threads: understanding the multiple effects of diversity in organizational groups. Academy of Management Review, 21(2), 402-433. doi: $10.2307 / 258667$ 
Nibler, R., \& Harris, K. L. (2003). The effects of culture and cohesiveness on intragroup conflict and effectiveness. The Journal of Social Psychology, 143(5), 613-631. doi: $10.1080 / 00224540309598467$

Nijdam, N. E. (1998). The functioning of work teams (Unpublished master's thesis). University of Amsterdam, Netherlands.

O'Connell, M. S., Doverspike, D., \& Cober, A. B. (2002). Leadership and semiautonomous work team performance: a field study. Group \& Organization Management, 27(1), 50-65. doi: $10.1177 / 1059601102027001004$

Pelled, L. H. (1996). Relational demography and perceptions of group conflict and performance: a field investigation. International Journal of Conflict Management, 7(3), 230-246. doi: $10.1108 / \mathrm{eb} 022783$

Pelled, L. H., Eisenhardt, K. M., \& Xin, K. R. (1999). Exploring the black box: an analysis of work group diversity, conflict, and performance. Administrative Science Quarterly, 44(1), 1-28. doi: $10.2307 / 2667029$

Podsakof, P. M., \& Organ, D. W. (1986). Self-reports in organizational research: problem and prospects. Journal of Management, 12(4), 531-544. doi: 10.1177/014920638601200408

Podsakoff, P. M., MacKenzie, S. B., Lee, J. Y., \& Podsakoff, N. P. (2003). Common method biases in behavioral research: a critical review of the literature and recommended remedies. Journal of Applied Psychology, 88(5), 879-903. doi: 10.1037/0021-9010.88.5.879

Pondy, L. R. (1967). Organizational conflict: concepts and models. Administrative Science Quarterly, 12(2), 296-320. doi: 10.2307/2391553

Ross, R. S. (1989). Conflict. In R. S. Ross \& J. R. Ross (Eds.), Small Groups in Organizational Settings (pp. 139-78). Englewood Cliffs, NJ: Prentice-Hall.

Schippers, M. C., Den Hartog, D. N., Koopman, P. L., \& Wienk, J. A. (2003). Diversity and team outcomes: the moderating effects of outcome interdependence and group longevity and the mediating effect of reflexivity. Journal of Organizational Behavior, 24(6), 779-802. doi: $10.1002 /$ job. 220

Schwenk, C. R. (1990). Effects of devil's advocacy and dialectical inquiry on decision making: a meta-analysis. Organizational Behavior and Human Decision Processes, 47(1), 161-176. doi: 10.1016/0749-5978(90)90051-A

Shenkar, O., \& Ronen, S. (1987). The cultural context of negotiation: the implication of Chinese interpersonal norms. Journal of Applied Behavioral Science, 23(2), 263-275. doi: $10.1177 / 0021886387232009$

Silva, N. I. A. (2009). Conflitos intragrupos: preditores e consequententes no cenário de equipes de trabalho (Unpublished master's thesis). Universidade de Brasília, Brasília, DF, Brazil.

Sobral, F., Carvalhal, E., \& Almeida, F. (2008). The influence of culture on negotiation styles of Brazilian executives. Management Research, 6(2), 107-120. doi: 10.2753/JMR15365433060203

Staw, B. M., Sandelands, L. E., \& Dutton, J. E. (1981). Threat rigidity effects in organizational behavior: a multilevel analysis. Administrative Science Quarterly, 26(4), 501-524.

Tabachnick, B. G., \& Fidell, L. S. (2000). Using multivariate statistics (4th ed.). Boston: Allyn \& Bacon. 
Tjosvold, D. (1991). Rights and responsibilities of dissent: cooperative conflict. Employees Responsibilities and Rights Journal, 4(1), 13-23. doi: 10.1007/BF01390435

Tjosvold, D., Law, K. S., \& Sun, H. (1999). Managing relational and task conflicts for team productivity in China [Unpublished manuscript]. Lingnan University, Hong Kong, China.

Tsui, A. S., Egan, T. D., \& O'Reilly, C. A. (1992). Being different: relational demography and organizational attachment. Administrative Science Quarterly, 37(4), 549-569.

Van de Vliert, E., \& De Dreu, C. K. W. (1994). Optimizing performance by conflict stimulation. International Journal of Conflict Management, 5(3), 211-222. doi: 10.1108/eb022743

Van der Vegt, G. S., Van de Vliert, E., \& Huang, X. (2005). Location-level links between diversity and innovative climate depend on national power distance. Academy of Management Journal, 48(6), 1171-1182. doi: 10.2307/20159736

Vermeul, L. (1996). The functioning of work teams in organizations: a study into the relations between group cohesion, conflict, performance, and satisfaction (Unpublished master's thesis). University of Amsterdam, Netherlands.

Webber, S. S., \& Donahue, L. M. (2001). Impact of highly and less job-related diversity on work group cohesion and performance: a meta-analysis. Journal of Management, 27(2), 141-162. doi: $10.1177 / 014920630102700202$

Westwood, R. I., Tang, S. F. Y., \& Kirkbride, P. S. (1992). Chinese conflict behavior: cultural antecedents and behavioral consequences. Organization Development Journal, 10(2), 13-19.

Williams, K., \& O’Reilly, C. A. (1998). Demography and diversity in organizations: a review of 40 years of research. In B. M. Staw \& L. L. Cummings (Eds.), Research in organizational behavior (Vol. 20, pp. 77-140). Greenwich, CT: JAI Press.

Wu, J. B., Tsui, A. S., \& Kinicki, A. J. (2010). Consequences of differentiated leadership in groups. Academy of Management Journal, 53(1), 90-106. doi: 10.5465/AMJ.2010.48037079 